\title{
A NECESSIDADE DE IMPLEMENTAÇÃO DE UM PROCESSO DECISÓRIO DELIBERATIVO ACERCA DA DESVINCULAÇÃO DE RECEITAS DA UNIÃO
}

THE NEED TO IMPLEMENT A DELIBERATIVE DECISION-MAKING PROCESS ON THE DISASSOCIATION OF UNION REVENUES

\section{LA NECESIDAD DE IMPLEMENTACIÓN DE UN PROCESO DECISORIO DELIBERATIVO SOBRE LA DESVINCULACIÓN DE HACIENDA PÚBLICA}

\section{Antonio Bazilio Floriani Neto ${ }^{1}$ Oksandro Osdival Gonçalves²}

Licença CC BY:

Artigo distribuído sob os termos Creative

Commons, permite uso e distribuição irrestrita em qualquer meio desde que o autor credite a fonte original.

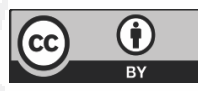

\begin{abstract}
Resumo: O presente artigo procura demonstrar que questões complexas, tais como o financiamento da Seguridade Social e o impacto gerado pela desvinculação de receitas da União (DRU), exigem uma deliberação entre as partes envolvidas, demandando respostas institucionais elaboradas de modo dialógico. Busca-se, neste estudo, demonstrar a importância de um intercâmbio entre as partes, a fim de estabelecer um raciocínio público e, assim, deliberar sobre a possibilidade de desafetar parcela do arrecadado pela Seguridade Social. Utiliza-se essa perspectiva para enaltecer não só a deliberação, mas o sentimento de justiça em matéria previdenciária. Adota-se uma abordagem descritiva fundada em técnicas da pesquisa bibliográfica.
\end{abstract}

Palavras-chave: Desvinculação de Receitas da União; Esfera Pública; Democracia Deliberativa.

1 Doutorando e mestre em Direito Econômico pela PUCPR, Curitiba, Paraná, Brasil. Possui graduação em direito e especialização em direito previdenciário pela PUC/PR. Professor universitário. Advogado. Endereço eletrônico: antonio@rochaefloriani.com.br

2 Professor do Programa de Pós-Graduação em Direito (Mestrado/Doutorado) da Pontifícia Universidade Católica do Paraná, Curitiba, Paraná, Brasil. Mestrado em Direito Econômico pela PUCPR; Doutorado em Direito pela PUCSP; pós-doutorado na Faculdade de Direito da Universidade de Lisboa. Advogado. Endereço eletrônico: oksandro@oksandro.adv.br 
Novos Estudos Jurídicos

\begin{abstract}
This article aims to demonstrate that complex issues such as the financing of social security and the impacts generated by the disassociation of EU revenues (DRU) demand a resolution between the parties, requiring institutional responses through dialog. As a consequence, this study demonstrates the importance of an exchange between the parties to establish a public reasoning and thus decide on the possibility of removing a portion of the Social Security revenues. This perspective is used to extoll not only the deliberation, but the sense of justice in social security. It adopts a descriptive approach based on the technique of a literature review.
\end{abstract}

Keywords: Disassociation of Union Revenues; Public Sphere; Deliberative Democracy.

Resumen: El presente artículo busca demonstrar que cuestiones complejas, tales como el financiamiento de la seguridad social y el impacto generado por la desvinculación de los ingresos de la Hacienda Pública (DRU), exigen una deliberación entre las partes envueltas, demandando respuestas institucionales elaboradas de modo dialógico. Se busca, en este estudio, demostrar la importancia de un intercambio entre las partes, con el fin de establecer un raciocinio público y, así, deliberar sobre la posibilidad de desarmar la parte de lo recaudado por la seguridad social. Se utiliza esa perspectiva para enaltecer no solo la deliberación, sino el sentimiento de justicia en materia seguridad social. Se adopta un abordaje descriptivo fundado en técnicas de investigación bibliográfica.

Palabras-clave: Desvinculación de ingresos públicos; Esfera Pública; Democracia Deliberativa.

\title{
INTRODUÇÃO
}

A Previdência Social brasileira é financiada de forma direta pelas contribuições sociais e o traço característico dessa espécie tributária é a destinação do produto arrecadado. Fala-se em espécie tributária com amparo no posicionamento do Supremo Tribunal Federal ${ }^{3}$, em que pese a matéria encontrar controvérsia em âmbito doutrinário4.

Contudo, doutrina e jurisprudência são unânimes acerca da necessidade de controle do momento posterior ao da arrecadação, devendo o produto desses ingressos ser utilizado para fins previdenciários.

Em que pese esse consenso, parte significativa do total arrecadado a título das contribuições sociais é desafetado pela Desvinculação de Receitas da

3 Conforme se observa no RE 566007 RG, Relator(a): Min. CÁRMEN LÚCIA, julgado em 13/05/2010, DJe-116 DIVULG 24-06-2010 PUBLIC 25-06-2010 EMENT VOL-02407-05 PP-01043 LEXSTF v. 32, n. 379, 2010, p. 219225 RET v. 13, n. 75,2010 , p. 123-127.

4 A título exemplificativo, cita-se GRECO, Marco Aurélio. Contribuições: uma figura sui generis. São Paulo: Dialética, 2000. 


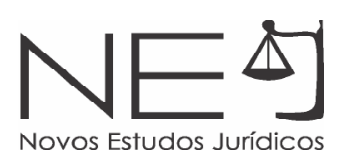

União (DRU), prevista no artigo 76, do ato dos dispositivos constitucionais transitórios (ADCT).

Consequentemente, a União tem autonomia para empregar o dinheiro arrecadado para outras finalidades, demonstrando existir equilíbrio financeiro e atuarial no sistema de Seguridade Social.

Em contrapartida, é recorrente a notícia acerca do deficit previdenciário, a necessidade de reformas e de serem tomadas medidas para equalizar as contas. Um exemplo disso foi a instituição da contribuição previdenciária sobre os inativos e as discussões envolvendo a mudança das regras necessárias para concessão das aposentadorias.

Logo, observa-se contradição nos argumentos postos, pois se de um lado autoriza-se o corrompimento do total arrecadado, de outro são tomadas medidas mais restritivas em relação aos segurados.

Nesse contexto, a fim de auxiliar o debate envolvendo o financiamento da Seguridade Social, o presente artigo propõe o resgate da esfera pública para que os cidadãos possam dialogar e debater sobre o processo de formação da vontade política. Para atingir o objetivo proposto, este trabalho é dividido em três partes, adotando-se o percurso metodológico dedutivo.

Na primeira parte, apresenta-se a forma de financiamento da Seguridade Social e o impacto ocasionado pela DRU. Nesse tópico é conferida especial atenção à proposta de emenda à Constituição, a qual não observou o regimento interno da câmara dos deputados e a sua aprovação pelo Senado, ensejando a EC 93/2016.

Em um segundo momento, a proposta é apresentar, brevemente e com amparo na doutrina de Hannah Arendt e Habermas, a importância do resgate da esfera pública, colocada em descrédito pela modernidade, o que compromete a informação dos cidadãos e o espírito de cidadania. Aqui, também será analisada a tensão existente entre os ideais democráticos e do constitucionalismo, suscitados por Gargarella.

Finalmente, buscar-se-á apresentar o conceito de democracia deliberativa com amparo na doutrina de Ralws, Habermas, Nino, Gargarella e Godoy, a fim 
de demonstrar a necessidade de uma discussão entre os atores político-sociais e, assim, conciliar o estado de direito e a soberania popular para se chegar a decisões moralmente mais justas em matéria previdenciária.

\section{O FINANCIAMENTO DA SEGURIDADE SOCIAL E O IMPACTO DA DRU}

Compreendida como um conjunto de ações destinadas a assegurar os direitos nas áreas da saúde, previdência e assistência, a Seguridade Social brasileira é prevista no texto constitucional de 1988 em seu artigo 194.

Optou o constituinte de 1988 por alicerçar a rede protetiva em duas bases: (i) no instrumento tributário e (ii) no próprio orçamento estatal. Essa assertiva torna-se mais evidente ao se examinar o artigo 195, da Constituição, dispositivo que racionaliza a forma de financiamento da Seguridade Social brasileira, a qual pode ocorrer de forma direta e indireta.

O financiamento indireto advém dos orçamentos provenientes da União, dos Estados, do Distrito Federal e dos Municípios. Já o financiamento direto é oriundo das contribuições sociais. Nota-se, portanto, que diferentemente do que muitos pensam, a Seguridade Social não é abastecida, única e exclusivamente, pelas contribuições sociais, haja vista existirem os recursos provenientes dos entes anteriormente destacados.

A acentuada preocupação do constituinte com o orçamento da Seguridade Social é exposta, também, no §5o, do artigo 195, cuja redação é a seguinte: "nenhum benefício ou serviço da seguridade social poderá ser criado, majorado ou estendido sem a correspondente fonte de custeio total".

Logo, a ordem constitucional estabelecida em 1988 impôs, expressamente, que a precedência da fonte de custeio deve servir de parâmetro a na criação, na majoração ou na extensão de prestações fornecidas pelos regimes previdenciários brasileiros.

E esse enfoque conferido pela Constituição é plenamente compreensível. Diz-se isso, porque as contribuições sociais representam importante parte do orçamento federal brasileiro, além do fato de que a sua arrecadação vem aumentando substancialmente, conforme doravante se expõe. 
Ao se examinara página do Tesouro Nacional na internet, mais especificamente o item "Receitas Primárias do Governo Central"5, observa-se que a arrecadação mensal da Previdência Social, em 01/1997 era de R\$3,5 bilhões. Já em 11/2015 a arrecadação mensal das contribuições sociais passou para $\mathrm{R} \$ 25,9$ bilhões.

E apesar desta maior transferência monetária para cofres públicos, é corriqueira a notícia veiculada na mídia acerca do deficit na Previdência Social brasileira6. Logo, há um conflito de informações: como se arrecada cada vez mais e "permanece" o rombo? Haveria um gradativo aumento na concessão de benefícios, responsável por majorar as despesas do Instituto Nacional de Seguro Social (INSS)? Ou então outros motivos conduzem a esta situação?

De acordo com o estudo "Análise da Seguridade Social 2014", realizado pela Associação Nacional dos Auditores Fiscais da Receita Federal do Brasil, a desvinculação de receitas da união (DRU) é um, senão o principal motivo, eis que foi responsável por subtrair do orçamento da Seguridade Social em 2014 a quantia de $\mathrm{R} \$ 63,2$ bilhões de reais7.

Vale lembrar, ainda, que quando se abordam as contribuições sociais, é indispensável o exame do momento posterior ao da arrecadação, pois é a destinação que as difere das demais espécies tributárias, como o imposto, por exemplo8.Por conta disso, Andrei Pitten Velloso e Leandro Paulsen aduzem que a desafetação ocasiona uma metamorfose jurídica na exação 9.

5 BRASIL. Secretaria do Tesouro Nacional. Receitas Primárias do Governo Central. Disponível em: <http:// www3.tesouro.fazenda.gov.br/series_temporais/Visualizacao.aspx?mudarperiodicidade=N\&variacaoabsoluta= N\&nabsoluta=\&variacaopercentual=N\&npercentual=\&mediamovel=N\&nmedia=\&metodomedia=Selecione $\% 20$ o\%20M\%C3\%A9todo\&periodicidade=Selecione \%20a\%20Mudan \%C3\%A7a\&metodo=Selecione $\% 200 \% 20$ Crit\%C3\%A9rio\&novabase=\&indice=N\&deflacionar=N\&strdeflator=Selecione\%20o\%20Deflator\&deflator=\&based eflator=\&inicio=\&fim=> Acesso em: 20 jul. 2016.

6 Como por exemplo se observa nos seguintes links: BRASIL. Previdência Social. RGPS: Regime Geral de Previdência Social tem déficit de 51,3 bilhões em 2013. Disponível em: <http://www.previdencia.gov.br/noticias/ regime-geral-de-previdencia-social-tem-deficit-de-513-bilhoes-em-2013/>. Acesso em: 20 jul. 2016.

Revista Exame. Déficit da Previdência no $1^{\circ}$ semestre foi de R\$ 23 bi. Disponível em: <http://exame.abril.com. br/economia/noticias/deficit-da-previdencia-no-1o-semestre-foi-de-r-23-bi> Acesso em: 20 jul. 2016.

Estadão. Previdência fecha 2013 com deficit de R\$51,2 bilhões. Disponível em: <http://economia.estadao.com. br/noticias/geral,previdencia-fecha-2013-com-deficit-de-r-51-2-bilhoes,176679e> Acesso em: 20 jul. 2016.

7 Análise da Seguridade Social 2014/Associação Nacional dos Auditores-Fiscais da Receita Federal do Brasil e Fundação ANFIP de Estudos da Seguridade Social - Brasília: ANFIP, 2015, p. 135. Disponível em: <http://www. anfip.org.br/publicacoes/20150713162859_Analise-da-Seguridade-Social-2014_13-07-2015_20150710-AnliseSeguridade-2014-Verso-Final.pdf>. Acesso em 20 jul. 2016.

8 DE SANTI, Eurico Marcos Diniz; CANADO, Vanessa Rahal. Direito Tributário e direito financeiro? Reconstruindo o conceito de tributo e resgatando o controle da destinação. In: Curso de direito tributário e finanças públicas: do fato à norma, da realidade ao conceito jurídico. $1^{\mathrm{a}}$ edição, $2^{\mathrm{a}}$ tiragem, 2009. p. 621.

9 PAULSEN, Leandro; VELLOSO, Andrei Pitten. Contribuições: teoria geral, contribuições em espécie. Porto Alegre: Livraria do Advogado Editora, 2013. p. 61. 
Apesar disso, desde a Emenda Constitucional de Revisão 1/94, uma parcela das receitas das contribuições sociais vem sendo desvinculada. Inicialmente para um fundo social de emergência e, a contar, de 2000, foi criada especificamente a desvinculação de receitas da União (DRU) por força da EC 27/0010.

Posteriormente, foram sendo publicadas diversas emendas constitucionais, sempre elastecendo a desvinculação de $20 \%$ da arrecadação de impostos, contribuições sociais e de intervenção no domínio econômico.

A subtração compromete o equilíbrio financeiro e atuarial do sistema de Seguridade Social, além de afetar diretamente a organização de um fundo solidário de gerações ${ }^{11}$. Em outros termos, se nem os direitos da presente geração são levados a sério, quem dirá os direitos das futuras gerações, pois os recursos são desviados para fins estranhos à função assecuratória' ${ }^{12}$.

Não bastasse tal, o próprio Senado Federal informa, em seu site, que a principal fonte de recursos da DRU é oriunda das contribuições sociais, as quais representam $90 \%$ do total desvinculado ${ }^{13}$.

Consequentemente, são adotadas medidas mais restritivas em relação aos benefícios, os quais possuem caráter alimentar, afetando a parte mais fraca da relação previdenciária: o segurado. Como exemplo, pode-se citar a imposição da contribuição para servidores inativos, autorizada pela Emenda Constitucional $41 / 2003^{14}$. Sob o argumento da crise econômica, alguns estados passaram a cobrar a exação, procedimento que tem sua constitucionalidade questionada, além de ofender o ato jurídico perfeito, o direito adquirido, o princípio da confiança, da

10 SAVARIS, José Antonio. Uma teoria da decisão judicial da Previdência Social: contributo para superação da prática utilitarista. Tese (doutorado). Departamento de direito do trabalho e previdência social. USP. São Paulo, 2010. p. 120

11 SAVARIS, José Antonio. Uma teoria da decisão judicial da Previdência Social: contributo para superação da prática utilitarista. p. 121.

12 SAVARIS, José Antonio. Uma teoria da decisão judicial da Previdência Social: contributo para superação da prática utilitarista. p. 188.

13 BRASIL. Senado Federal. Agência Senado. DRU. Disponível em: <http://www12.senado.leg.br/ noticias/entendao-assunto/dru> Acesso em: 20 jul. 2016.

14 A contribuição foi instituída pela Lei 9.983/1999, que foi considerada inconstitucional pelo STF na análise da ADI n. 2.010. Posteriormente, o Congresso Nacional, valendo-se dos argumentos do Pretório Excelso, editou a EC 41.2003. A matéria voltou a ser examinada pela Suprema Corte, por meio da ADI n. 3.105, ocasião em que o procedimento foi considerado constitucional. Apesar da decisão favorável, diversos estados não instituíram a cobrança aos aposentados, o que somente veio a ocorrer no Paraná, por exemplo, mais de uma década após o julgado. Sobre o tema ver: GABARDO, Emerson; VALIATI, Thiago. A inconstitucionalidade da instituição de contribuição previdenciária para servidores inativos. Revista de Direito Administrativo, v. 270, p. 243-282, 2015. 
boa-fé dos servidores inativos, dentre outros ${ }^{15}$. Nota-se, assim, contradição no argumento da necessidade de equalizar as contas com a imposição de nova contribuição e, mesmo assim, desvincular percentual das receitas orçamentárias da Seguridade Social.

De volta à DRU, em 21/12/2011 foi publicada a Emenda Constitucional 68, que a prorrogou até $31 / 12 / 2015$. Prestes a haver sua cessação, foi encaminhada nova emenda pelo Executivo Federal para estabelecer novos contornos à DRU, aumentando o percentual para 30\%.

\subsection{A PRORROGAÇÃO DA DRU}

$\mathrm{Na}$ data de 01/07/2015 foi submetida ao Congresso Nacional, pelo governo federal, a proposta de emenda à Constituição (PEC) 87/2015, com o objetivo de prorrogar a DRU até 2023. Além disso, a PEC objetivava aumentar para $30 \%$ o percentual desvinculado.

A proposta foi apensada à PEC 4/2015 16 e aprovada, em segundo turno, pela Câmara dos Deputados em 08/06/2016 ${ }^{17}$, contabilizando 340 votos favoráveis e 96 contrários.

Interessante ressaltar que a primeira votação ocorrida na Câmara ocorreu apenas 6 (seis) dias antes, em 02/06/2016. Nesse contexto, o exíguo prazo havido entre os dois turnos contrariou expressamente o regimento da Câmara, que em seu artigo 201, $\S 6^{\circ}$ estabelece, expressamente, que a proposta de emenda à Constituição, além de necessitar ser submetida a dois turnos de discussão e votação, deve haver um interstício de 5 (cinco) sessões entre ambos.

O requerimento foi proposto pelo líder do governo no dia 07/06/2016 e aprovado de imediato ${ }^{18}$. No dia seguinte, houve a segunda deliberação e, consequentemente, foram estabelecidos os novos contornos da DRU.

15 GABARDO, Emerson; VALIATI, Thiago. A inconstitucionalidade da instituição de contribuição previdenciária para servidores inativos. p. 243-246.

16 BRASIL. Câmara dos Deputados. Projetos de Lei e outras proposições. PEC 87/2015. Disponível em: <http://www. camara.gov.br/proposicoesWeb/fichadetramitacao?idProposicao= 1567815> Acesso em: 20 jul. 2016.

17 BRASIL. Câmara dos Deputados. Projetos de Lei e outras proposições. PEC 4/2015. Disponível em: <http://www. camara.gov.br/proposicoesWeb/prop_mostrarintegra?codteor $=$ 1465821\&filename=Tramitacao-PEC+4/2015> Acesso em: 20 jul. 2016.

18 BRASIL. Câmara doa Deputados. Discursos e Notas Taquigráficas - Sessão: 140.2.55.0. Disponível em: <http://www.camara.leg.br/internet/sitaqweb/TextoHTML.asp?etapa=3\&nuSessao $=140.2 .55 .0 \&$ nuQuarto $=7 \&$ nu Orador=1\&nulnsercao=0\&dtHorarioQuarto $=20: 20 \&$ sgFaseSessao $=\mathrm{BC} \% 20 \% 20 \% 20 \% 20 \% 20 \% 20 \% 20 \% 20 \& \mathrm{Da}$ ta $=07 / 06 / 2016 \&$ txApelido=PRESIDENTE\&txFaseSessao=Breves $\% 20$ Comunica $\%$ C3 $\% A 7 \% C 3 \% B 5$ es $\% 20 \% 20$ \%20\%20\%20\%20\%20\%20\%20\%20\%20\&dtHoraQuarto=20:20\&txEtapa=Com\%20reda\%C3\%A7\%C3\%A3o\%20 final> Acesso em: 20 jul. 2016. 
Vale destacar que a PEC foi examinada e aprovada pelo Senado Federal, ensejando a Emenda Constitucional 93/2016, que alterou o artigo 76, do ADCT e prorrogou a DRU até 2023, retirando 30\% do total arrecadado a título de contribuições sociais, de intervenção no domínio econômico e taxas.

Esse ato, além de ser contraditório com o suposto deficit da Previdência Social, chama atenção pela urgência inerente ao procedimento. A justificativa apresentada foi a de que, com o aumento do percentual, haverá possibilidade de atender de forma mais célere as demandas da sociedade e garantir recursos aos projetos prioritários.

No entanto, tal mudança deveria ser precedida de um amplo debate entre a sociedade, a fim de que fossem ouvidos segurados, empregados, empregadores, centrais sindicais, especialistas, empresas, até porque em um estado democrático de direito vige o princípio do não retrocesso, que de acordo com Canotilho, impede a reversibilidade dos direitos adquiridos, mesmo em momentos de recessões econômicas19.

Sabe-se que, em momentos de crises, devem ser feitos ajustes orçamentários e a matéria previdenciária sempre contemplou essas mudanças, especialmente porque deve refletir a mudança ocorrida na sociedade: a população tem vivido mais, as famílias estão menos numerosas e todas esses dados demográficos afetam o sistema de Seguridade Social.

De outro giro, são os beneficiários desse sistema os afetados por quaisquer mudanças havidas na legislação. E antes de segurados, os indivíduos são cidadãos e merecem a oportunidade de participar ativamente na vida pública, ainda mais em tema como esse relativo à DRU, a fim de evitar medidas absolutamente intempestivas. Assim, apesar do suposto deficit, são tomadas medidas pelo governo para majorar o percentual a ser desvinculado do fundo previdenciário para 30\%. E pior, no caso específico da DRU, a deliberação acerca da sua prorrogação na PEC 4/2015 ocorreu sem respeitar o regimento interno da Câmara dos Deputados, privilegiando a celeridade a o interesse da União em detrimento da deliberação da sociedade, que poderia ocorrer por meio de audiências públicas, por exemplo.

19 CANOTILHO, José Joaquim Gomes. Direito constitucional e teoria constitucional. 2. ed. Coimbra, Almedina, 1988. p. 224. 
Por conta disso, parte-se do pressuposto de que o tema não envolve critérios exclusivamente econômicos e o imbróglio pode ser atenuado com uma maior participação do povo na vida pública.

Nesse contexto, ganha espaço a democracia deliberativa. Para que esta seja eficaz, indispensável o resgate da esfera pública, tema abordado no próximo item.

\section{O NECESSÁRIO RESGATE DA ESFERA PÚBLICA E A TENSÃO EXISTENTE ENTRE DEMOCRACIA E CONSTITUCIONALISMO}

A esfera pública pode ser definida como o local onde os indivíduos relevam a sua singularidade, é o palco de confluência do agir e da palavra humana, esta última tem a pretensão de expor argumentos com razoabilidade e racionalidade para promover uma troca pública ${ }^{20}$. E o homem é, por natureza, um ser político, social. Arendt explica que, para os gregos, havia duas ordens de existência do homem: a natural, exercida em sua casa; e a comum, praticada pela ação e pelo discurso na polis ${ }^{21}$. Nesta última, os cidadãos eram reputados como iguais, vigiando a liberdade, ao passo que na família, a situação era oposta: o chefe exercia o domínio e, inclusive, poderia fazer uso da força. Para ser livre, necessitava da faculdade de ingressar na esfera pública. A autora explica que a sociedade moderna modificou a divisão entre o público e o privado, alterando o significado dos termos: quando se fala em privado atualmente, pensa-se no círculo de intimidade, ao passo que, antigamente, a vida privada significava na impossibilidade de participar da esfera pública ${ }^{22}$.

Com a modernidade, os homens perdem a capacidade política junto à esfera pública, gerando uma sociedade despolitizada, solitária, comprimida em massa. Os cidadãos passam a agir pela necessidade, a propriedade passou a representar riqueza e, assim, condicionar à participação política. Assim, prevaleceu a ideia de esfera pública como arena de disputa entre grupos de poder, de modo que a

20 VALLADARES, Christiane. A esfera pública e a política segundo Hannah Arendt. Monografia (Curso de Especialização em Instituições e Processos Políticos do Legislativo). Brasília: Centro de Formação e Aperfeiçoamento Câmara dos Deputados, 2009. Disponívelem:<http://www2.camara.leg.br/responsabilidadesocial/ edulegislativa/educacao-legislativa-1/ posgraduacao/arquivos/publicacoes/bancodemonografias/ip-3a-edicao/ ChristianeAparecida SilvaValladaresIP3ed.pdf>. p. 24.

21 ARENDT, Hannah. A condição humana. Tradução de Roberto Raposo, posfácio de Celso Lafer. Rio de Janeiro: Forense Universitária, 2007. p. 33-35.

ARENDT, Hannah. A condição humana. p. 46-48. 
sociedade assumiu um disfarce para organização de proprietários, restando ao indivíduo exercer sua vontade por meio do voto23.

Habermas dedicou-se ao estudo da esfera pública, reputando-a como uma rede comunicativa, em que os indivíduos expõem pontos de vista, comunicamse e, assim, estabelecem filtros que formam opiniões públicas24. O autor enfatiza que a esfera pública não pode ser entendida como uma instituição, tampouco uma organização, pois não é formada por uma estrutura normativa responsável por elencar papéis de atuação ou estabelecer competências. Seus horizontes são abertos, deslocáveis, permeáveis, conduzidos pelos fluxos comunicativos 25 .

Com o advento de novas tecnologias de comunicação, da mídia de massas, da formação de grupos de poder, houve o fenômeno de desintegração da opinião pública. O público, de pensador de cultura, passa a consumi-la, abrindo espaço para um clima em que se perde a comunicação e, assim, tornando discussões inócuas26.

Consequentemente, há a crise da democracia representativa, formada por uma opinião pública "débil e artificial", com funções políticas da esfera pública fragilizadas27. E isso afeta o regime democrático, o qual deve ser fundado na vontade do povo.

Vale destacar que os textos constitucionais contemporâneos têm como característica elencar a democracia como princípio basilar, especialmente por incutirem como núcleo base a soberania do povo28. No entanto, por mais estranho que possa soar, há uma tensão entre os ideais democráticos e do constitucionalismo, de modo que seus desacordos repercutem nas mais variadas discussões políticas 29.

23 ARENDT, Hannah. A condição humana. p. 74-78.

24 HABERMAS, Jurgen. Direito e democracia: entre facticidade e validade, volume I. Tradução: Flávio Beno Siebeneichler. Rio de Janeiro: Tempo Brasileiro, 1997. p. 92

25 HABERMAS, Jurgen. Direito e democracia. p. 92.

26 HABERMAS, Jurgen. Mudança estrutural da esfera pública: investigações quanto a uma categoria da sociedade burguesa. Tradução de Flávio R. Kothe. Rio de Janeiro: Tempo Brasileiro, 2003. 190-193.

27 JACOB NETO, Elias; CADEMARTORI, Daniela Mesquita Leutchuk de. Poder, Meios de Comunicação de Massas e Esfera Pública na Democracia Constitucional. Sequência, v. 34, p. 187-212, 2013. p. 191-192.

28 GODOY, Miguel Gualano de. Constitucionalismo e democracia: uma leitura a partir de Carlos Santiago Nino e Roberto Gargarella. São Paulo: Saraiva, 2012. p. 54.

29 GARGARELLA, Roberto. Constitucionalismo vs. Democracia. In: ZAMORA, Jorge Luis Fabra; SPECTOR, Ezequiel. Enciclopedia de filosofia y teoria del derecho. Volumen três. México: Universidad Nacional Autónoma de México, 2015. p. 1991-2010. p. 1991. 
Gargarella ensina que o conflito advém do fato de ambas ideias apelarem a princípios opostos: os compromissos democráticos refletem a concepção de que não haveria nenhuma autoridade, atuando coletivamente, superior à nossa, ou seja, podem conduzir a um princípio que, aparentemente, não teria limites.

De outro lado, há a superioridade da Constituição, dos seus dispositivos e das suas diretrizes, como os direitos humanos, que levam ao raciocínio oposto: existem limites que devem, necessariamente, permanecer incólumes a pressões de grupos, especialmente os majoritários ${ }^{30}$.

Nesse contexto, há momentos em que se quer estar apegado ao direito, que é exibido de forma rígida na Constituição ${ }^{31}$ : o anseio popular é justamente estar sujeito somente a regras impessoais e não a uma vontade discricionária. Porém, há situações em que se encontra preso ao ordenamento jurídico ${ }^{32}$. Esta última situação pode ser ilustrada pelas mudanças e pela dinamicidade de uma sociedade plural, complexa e que está em constante transformação. É nesse embate que são conjugados direito e política.

E vale lembrar que indivíduo e Estado pertencem a um processo denominado sociedade ${ }^{33}$. Consequentemente, é impossível separar a racionalidade estatal da do indivíduo, pois ambos fazem parte de um contexto. Se o texto constitucional é permeado por dispositivos e categorias jurídicas, vale lembrar que o seu campo de abrangência envolve toda a sociedade e não só o Estado ${ }^{34}$. Ademais, são em momentos de efetivação da ordem constitucional em que se nota a manifestação da política. Verifica-se o caráter dinâmico que "'politiza' o conceito de Constituição" 35 .

O problema, bem delineado por Gabardo, é a tendência moderna de contrapor estas duas partes: "atualmente é o Estado que está desvalorizado na medida em que, cada vez mais, é recuperado o prestígio do indivíduo"36. Assim, a esfera

30 GARGARELLA, Roberto. Constitucionalismo vs. Democracia. p. 1991.

31 GODOY, Miguel Gualano de. Constitucionalismo e democracia: uma leitura a partir de Carlos Santiago Nino e Roberto Gargarella. p. 54.

32 GARGARELLA, Roberto. Constitucionalismo vs. Democracia. p. 1992.

33 GABARDO, Emerson. Interesse público e subsidiariedade: o Estado e a sociedade civil para além do bem e do mal. p. 102.

34 BERCOVICI, Gilberto. Constituição e política: uma relação difícil. Lua Nova. São Paulo, n. 61, p. 5-24. 2004. p. 9.

35 BERCOVICl, Gilberto. Constituição e política: uma relação difícil. p. 9

36 GABARDO, Emerson. Interesse público e subsidiariedade: o Estado e a sociedade civil para além do bem e do mal. p. 103. 
pública entra em descrédito e as pessoas perdem o interesse pela deliberação.

A Constituição de 1988 institui, em seu preâmbulo, um estado democrático de direito. Já no artigo $3^{\circ}$, no qual são elencados os objetivos da República Federativa do Brasil, está a construção de uma sociedade livre, justa, solidária; a erradicação da pobreza, a busca pelo desenvolvimento nacional e a promoção do bem de todos.

Observa-se, assim, que o estado contemplado não foi neutro e os objetivos insculpidos no texto constitucional assumem um "dever ser". O constituinte, portanto, revelou-se irresignado "[...] com a ordem econômica e social que encontrara, enumerando uma série de valores sobre os quais se deveria firmar o Estado, o qual, ao mesmo tempo, se dotaria de ferramentas hábeis a concretizar a ordem desejada" ${ }^{37}$.

Aqui, está incutida a ideia de constitucionalismo contemporâneo, que não abandona "o caráter protetivo do cidadão e limitador da atuação estatal" 38 , mas vai além. Não só prevê a liberdade, mas exige a sua realização, estabelecendo padrões mínimos para os cidadãos exercerem seus direitos com plenitude. A Constituição, nessa esteira, assume um papel muito além de mero instrumento de governo: deve estabelecer programas e definir diretrizes para o Estado e para a sociedade ${ }^{39}$.

Cresce, assim, a importância dos poderes legislativo e judiciário. O primeiro, pela responsabilidade de implementar as diretrizes constitucionais, que se não forem devidamente colocadas em prática, os indivíduos poderão socorrer-se ao judiciário. Esse poder, na ausência de regra constitucional específica para dirimir a controvérsia, será obrigado a aplicar um princípio constitucional, ou mais de $u^{40}$.

Para tanto, indispensável a presença de um poder judiciário independente, imparcial e hábil a se impor (aplicando a Constituição) diante de um conflito "[...] sob pena de sê-lo ineficaz, sujeito às pressões das maiorias e inerte em relação à eficácia normativa da Constituição"41.

37 SCHOUERI, Luís Eduardo. Normas tributárias indutoras e intervenção econômica. Rio de Janeiro: Forense, 2005. p. 1.

38 SCHOUERI, Luís Eduardo. Normas tributárias indutoras e intervenção econômica. p. 21.

39 BERCOVICI, Gilberto. Constituição e política: uma relação difícil. p. 10.

40 BERCOVICI, Gilberto. Constituição e política: uma relação difícil. p. 28.

41 GODOY, Miguel Gualano. Constitucionalismo e democracia: uma leitura a partir de Carlos Santiago Nino e Roberto Gargarella. p. 56. 
Ademais, é característica marcante de países que romperam com regimes autoritários, a reconstrução e a organização desse poder, a fim de que possa interpretar e aplicar a lei com base em princípios e técnicas jurídicas ${ }^{42}$.

Vale dizer, cabe ao Judiciário examinar eventual ameaça ou lesão a direito de alguém, realizar o controle de constitucionalidade, primando pela defesa da Constituição. Contudo, como lembra Godoy, tudo isso seria inócuo sem a democracia, que possui o papel de provocar, renovar e não acomodar o constitucionalismo ${ }^{43}$, especialmente após momentos de conquistas.

Conciliar democracia com constitucionalismo é, contudo, tarefa complexa e problemática, apesar dos conceitos serem indissociáveis ${ }^{44}$. A premissa se assenta pelo fato de que quando se fala no poder do povo para decidir questões acerca dos rumos da nação, tal agir envolve, necessariamente, o conteúdo da Constituição, ou seja, "[...] as normas que organizam as instituições do governo e estabelecem limites aos respectivos poderes governamentais" 45 . Consequentemente, a própria democracia deve levar em conta limites estabelecidos pelo poder constitucional, eis que nem tudo pode ser delegado à decisão majoritária.

Trata-se, portanto, de uma relação polêmica e que pode render profícuo debate, especialmente porque a democracia deliberativa renova o papel do constitucionalismo e, ao mesmo tempo, enseja uma reflexão da atuação do poder judiciário, que "[...] pode (e deve) atuar de forma mais democrática, dialógica, de modo a possibilitar e ampliar a participação popular nos processos de discussão e decisão" 46 .

Agindo assim, poderão ser corrigidas desigualdades e vícios que afetem, além de ser possível estabelecer uma nova forma de se encarar o controle judicial

42 BARROSO, Luís Roberto. Constituição, democracia e supremacia judicial: direito e política no Brasil contemporâneo.

Revista eletrônica sobre a reforma do estado (RERE). Salvador, Instituto brasileiro de direito público, $n^{\circ} 23$, setembro, outubro, novembro, 2010. Disponível em: < http://www.direitodoestado.com/revista/rere-23-setembro2010-luis-roberto-barroso.pdf>. Acesso em 01.jul. 2016. p. 16.

43 GODOY, Miguel Gualano. Constitucionalismo e democracia: uma leitura a partir de Carlos Santiago Nino e Roberto Gargarella. p. 56.

44 GODOY, Miguel Gualano. Constitucionalismo e democracia: uma leitura a partir de Carlos Santiago Nino e Roberto Gargarella. p. 23.

45 GODOY, Miguel Gualano. Constitucionalismo e democracia: uma leitura a partir de Carlos Santiago Nino e Roberto Gargarella. p. 24.

46 GODOY, Miguel Gualano. Constitucionalismo e democracia: uma leitura a partir de Carlos Santiago Nino e Roberto Gargarella. p. 24. 
de constitucionalidade das leis e, também, promover a efetividade dos direitos sociais e "os reclamos daqueles que só conseguem se fazer, ver e ouvir mediante atos de protesto" 47 .

Assim, chega-se à importância do diálogo, do resgate da esfera pública para, então, exercer a democracia deliberativa. No caso do financiamento da Seguridade Social, observa-se que o resgate da esfera pública seria indispensável para que os cidadãos pudessem conhecer melhor o sistema e, assim, reivindicar seus direitos e evitar com que fossem tomadas medidas intempestivas. Ouve-se a existência de deficit e o governo tem agido por meio de medidas provisórias. O exemplo mais recente foi a Medida Provisória 739/2016, que revogou o parágrafo único do artigo 24, da Lei 8.213/91 e agora o cidadão que perder a qualidade de segurado junto ao Regime Geral de Previdência Social (RGPS) e buscar a concessão de um benefício por incapacidade terá que contribuir 12 meses, quando antes 4 meses bastavam. Em 2015, também houve uma medida provisória, de n. 676, a qual modificou as regras necessárias para pensão por morte, estabelecendo um prazo de duração no relacionamento e no tempo a ser pago a título desse benefício.

Nota-se que todas as medidas partiram do Poder Executivo, valendo-se dos requisitos de relevância e urgência para atenuar esse suposto deficit previdenciário. Ocorre que, ao mesmo tempo, foi elevado o percentual da DRU para 30\%.

Assim sendo, em que pese ser necessária a reforma do sistema previdenciário brasileiro, a mudança não pode ocorrer por meio de Medidas Provisórias ou processos que não respeitam o ordenamento jurídico.

Acredita-se que o debate entre todos os envolvidos seria a melhor forma de direcionar e tornar justa a mudança, sendo necessário, portanto, o resgate da esfera pública e realizados amplos debates, especialmente no âmbito do poder legislativo.

Diz-se isso, pois se os cidadãos não confiarem mais na esfera pública, buscarão "[...] outras formas de reconhecimento moral que possam atender às

47 GODOY, Miguel Gualano. Constitucionalismo e democracia: uma leitura a partir de Carlos Santiago Nino e Roberto Gargarella. p. 24 
suas necessidades, desprestigiando o exercício da cidadania [...]"48. E isso em uma matéria como previdenciária é temeroso, pois o sistema de Seguridade Social é fundado no princípio da solidariedade, o qual traz a ideia de proteção coletiva, fazendo com que as contribuições do sujeito se destinem à manutenção de toda a rede protetiva e não só para sua tutela individual49. Logo, é imprescindível a superação do pensamento individualista, maximizador do bem-estar individual, para assumir feição coletiva. Nesse contexto, advém a importância do resgate da esfera pública.

Tecidas essas considerações, chega-se à democracia deliberativa.

\section{A DEMOCRACIA DELIBERATIVA E A IMPORTÂNCIA DAS DECISÕES COLETIVAS}

A democracia deliberativa é fundada na ideia de que é possível formular um acordo mútuo, capaz de satisfazer os ideais de racionalidade e legitimidade, por meio de processos deliberatórios ${ }^{50}$.

Kozicki elenca os três principais aspectos de uma democracia deliberativa: é um modo de organização do poder político, cidadãos devem participar do processo decisório e esta deliberação deve ser livre, além de ser formada por indivíduos considerados como iguais, tanto política, quanto moralmente ${ }^{51}$.

A experiência latino-americana, conforme explicam os professores Roberto Gargarella e Carlos Santiago Nino ${ }^{52}$, tem encontrado enormes dificuldades para atingir esse desiderato, como a presença de instituições políticas parciais, o domínio de elites há tempos no poder, a existência de políticos distantes do povo e movidos por interesses particulares, além dos momentos de quebra do ordenamento jurídico e, por fim, o longo histórico de desigualdades sociais.

Outro aspecto de dificuldade seria atingir um consenso em uma sociedade plural. Contudo, as variações ideológicas podem ocorrer, mas respeitando uma base, que pode ser formada pela democracia deliberativa.

48 GABARDO, Emerson. Interesse público e subsidiariedade: o Estado e a sociedade civil para além do bem e do mal. p. 74.

49 IBRAHIM, Fábio Zambitte. Curso de direito previdenciário. Rio de Janeiro: Impetus, 2011. p. 65.

50 KOZICKI, Katya. Democracia deliberativa: a recuperação do componente moral na esfera pública. Revista da Faculdade de Direito da UFPR. Curitiba. v. 41. 2004. p. 43-57. p. 45.

51 KOZICKI, Katya. Democracia deliberativa: a recuperação do componente moral na esfera pública. p. 48.

52 NINO, Carlos Santiago. La constitución de la democracia deliberativa. Buenos Aires: Gedisa, 1997. 
Nesse contexto, em um primeiro momento, é preciso estabelecer as bases do justo, para então, por meio da teoria do discurso, formular as proposições. Rawls e Habermas comungam desse posicionamento ${ }^{53}$, acreditando ser necessário o estabelecimento de bases de legitimidade da democracia e, para tanto, advém a deliberação. Essa forma de agir não implica, também, a premissa de que tudo deve ocorrer de forma procedimental ${ }^{54}$.

Rawls busca formular uma teoria de justiça com base nas teorias do contrato social, inspirado por Locke, Rousseau e Kant, porém desejando atingir um nível superior de abstração55. Para tanto, Rawls preconizou um mecanismo de acordo mútuo, realizado entre pessoas livres, racionais e em uma posição inicial de igualdade, cujos efeitos se elasteceriam futuramente, seja no tocante às formas de cooperação social, seja quanto às formas de governo. A essa concepção de princípios de justiça, denominou justiça como equidade56.

$\mathrm{Na}$ posição original da justiça como equidade, os cidadãos não têm conhecimento do local onde irão nascer, das suas famílias, das suas condições físicas, psicológicas, culturais. Trata-se de uma situação hipotética, em que a parte está envolta em um véu da ignorância, de modo a induzir determinada escolha acerca dos princípios da justiça: consequentemente ninguém será "[...] favorecido ou desfavorecido na escolha dos princípios pelo resultado do acaso natural ou pela contingência de circunstâncias sociais" 57 .

Consequentemente, os indivíduos escolherão dois princípios de justiça: todos devem ter acesso a um sistema de liberdades básicas iguais e as diferenças sociais e econômicas devem ser "(a) consideradas como vantajosas para todos dentro dos limites do razoável e (b) vinculadas a posições e cargos acessíveis a todos"58.

O primeiro, reflete a ideia das liberdades fundamentais, tais como a política, de

53 Apesar de divergirem quanto ao resultado: para Ralws, a ênfase está na análise dos resultados; já para Habermas, basta que o procedimento atenda aos requisitos estabelecidos. KOZICKI, Katya. Democracia deliberativa: a recuperação do componente moral na esfera pública. p. 43-57.

54 KOZICKI, Katya. Democracia deliberativa: a recuperação do componente moral na esfera pública. p. 48.

55 RAWLS, John. Uma teoria da justiça. Tradução: Almiro Pisetta e Lenita M. R. Esteves. São Paulo: Martins Fontes, 1997. p. 12. 
expressão, de reunião, de pensamento, as individuais e que devem ser iguais para todos. Já o segundo princípio, conforme elucida Godoy 59, merece ser examinado mediante a conjunção de outros dois princípios: o da igualdade equitativa de oportunidade e o princípio da diferença. Ambos estão ligados à distribuição de benefícios, de modo que somente haverá uma melhora na condição de alguém se houver o aprimoramento daquele que está em situação pior, devendo ambos ser aplicados "[...] sobre as instituições básicas da sociedade a fim de determinar a distribuição, os benefícios e encargos sociais aos indivíduos de uma sociedade" ${ }^{\prime 60}$.

Em resumo, Rawls, em sua teoria de justiça, "[...] procura reconciliar liberdade e igualdade (a liberdade dos modernos, de Locke, e a igualdade dos antigos, de Rousseau)"61, por meio da aplicação dos princípios de justiça, os quais podem servir de parâmetro para mudanças políticas. Assim, aproximam-se os princípios de justiça com o modelo procedimental de democracia.

Habermas, por sua vez, possui uma visão distinta acerca da democracia deliberativa ${ }^{62}$, focando as atenções na esfera pública, como local em que as normas são racionalizadas, debatidas e instaurado um processo decisório. Habermas entende que "o sistema político constituído pelo Estado de direito não gira em torno de si mesmo, mas permanece dependente de uma 'cultura política libertária' e de uma 'população acostumada à liberdade "'63. Para o autor, o processo democrático exige uma circunstância de direitos políticos fundamentais assumirem forma de direitos subjetivos-públicos, ensejando liberdades subjetivas de ação. Por conta disso, o estado moderno abre margem para os cidadãos decidirem como será o rumo da nação, por meio de um debate igualitário e, assim, podendo opinar sobre o bem comum ${ }^{64}$.

Em outros termos, somente com uma diversidade de perspectivas podese aprofundar em temas que envolvam questões éticas e morais e, para isso,

59 GODOY, Miguel Gualano. Constitucionalismo e democracia: uma leitura a partir de Carlos Santiago Nino e Roberto Gargarella. p. 83.

60 GODOY, Miguel Gualano. Constitucionalismo e democracia: uma leitura a partir de Carlos Santiago Nino e Roberto Gargarella. p. 84.

61 GODOY, Miguel Gualano. Constitucionalismo e democracia: uma leitura a partir de Carlos Santiago Nino e Roberto Gargarella. p. 87.

62 HABERMAS, Jurgen. Direito e democracia: entre facticidade e validade, volume I. Tradução: Flávio Beno Siebeneichler. Rio de Janeiro: Tempo Brasileiro, 1997.

63 HABERMAS, Jurgen. Direito e democracia: entre facticidade e validade. p. 311.

64 HABERMAS, Jürgen. A inclusão do outro: estudos de teoria política. Tradução de George Sperber, Paulo Soethe e Miltin C. Mota. 2. ed. São Paulo: Loyola, 2004. p. 311. 
Novos Estudos Jurídicos

imprescindível uma dinâmica entre indivíduos. Como consequência, rompe-se com a ideia da dogmática clássica do direito, que visualizava a pessoa de direito abstratamente, para atribuí-la uma identidade coletiva. Para tanto, Habermas apresenta a esfera pública presente na esfera pública "[...] como o espaço privilegiado em que as normas emergentes do mundo da vida são racionalizadas pela comunicação para então poderem por meio do processo decisório ter espaço no âmbito estatal" ${ }^{\prime \prime 5}$.

Tendo esses conceitos em mente, pode-se diferenciar os pensamentos de Habermas e Rawls: enquanto o alemão constrói um aporte eminentemente procedimental, o filósofo norte-americano parte de um mecanismo substantivo de democracia deliberativa, no qual se aplicam princípios anteriormente justificados ou escolhidos ${ }^{66}$.

Diz-se procedimental a concepção habermasiana, pois os próprios indivíduos poderão escolher os princípios a ser aplicados no curso de ação, ou seja, durante o procedimento de discussão. Para que isso seja possível, indispensável que todos sejam livres, iguais e interajam entre si. Essa interação, contudo, não deve ser pautada pela busca da maximização da vontade individual.

Esse modelo amplo de diálogo pode ser de grande valia quando há conflito normativo. Isso porque, de acordo com Habermas, em ordens jurídicas modernas, cabe aos cidadãos decidirem livremente sobre como fazer uso de seus direitos de comunicação e participação. O bem comum não pode ser uma obrigação jurídica e isso não implica que deva ser ignorado. Ele é necessário em certo grau, já que a atividade legislativa só pode legitimar-se a partir do processo de acordo mútuo ocorrido entre os cidadãos do estado quanto às regras do convívio entre eles ${ }^{67}$.

Contudo, Habermas parte de um modelo que proporciona efetiva participação dos sujeitos, a ausência de violência, coações externas e seriedade ${ }^{68}$. Tais condições, em um país como o Brasil, de grandes desigualdades econômicas

65 GODOY, Miguel Gualano de. Justiça. Democracia e Direitos Fundamentais: o liberalismo igualitário de John Rawls, o procedimentalismo e Jürgen Habermas e a proposta de Carlos Santiago Nino. In: XIX Encontro Nacional do Conselho Nacional de Pesquisa e Pós-graduação em Direito (CONPEDI), 2010, Fortaleza. Anais do XIX Encontro Nacional do Conselho Nacional de Pesquisa e Pós-graduação em Direito, 2010. p. 4545.

66 GODOY, Miguel Gualano de. Constitucionalismo e democracia: uma leitura a partir de Carlos Santiago Nino e Roberto Gargarella. p. 89.

67 HABERMAS, Jürgen. A inclusão do outro: estudos de teoria política. p. 312-313.

68 GODOY, Miguel Gualano de. Constitucionalismo e democracia: uma leitura a partir de Carlos Santiago Nino e Roberto Gargarella. p. 90. 
e sociais, em que parcela significativa da população está à margem do processo decisório, devem ser examinadas com ressalvas.

De outro giro, tal premissa não implica a conclusão de que o aporte de Habermas deva ser rechaçado ${ }^{69}$. Nesse contexto, Godoy propõe uma democracia deliberativa para além de Rawls e Habermas, valendo-se da doutrina de Carlos Santiago Nino e Roberto Gargarella.

Oautorexpõe, com precisão, que Rawlspreconizauma democracia deliberativa substantiva, eis que enfatiza os resultados do procedimento democrático deliberativo ${ }^{70}$. Habermas, por sua vez, funda sua teoria com a concepção de que o discurso é formado por interações comunicativas, proporcionando o debate dos sujeitos, diferentes argumentos, valorizando, assim, "[...] o núcleo normativo da ética do discurso, a esfera pública como espaço legítimo de discussão"71.

Consequentemente, se o homem é dotado de reflexão crítica, pode dialogar em igualdade de condições com outro e é por meio desse exercício que a sociedade fixará a moralidade de uma norma72.

Mas há o posicionamento de Gargarella e Nino. Nino adota uma posição intermediária, valendo-se dos conceitos de Habermas, Rawls e indo além, acreditando que "[...] o conhecimento da verdade moral se dá a partir de um procedimento que privilegie uma discussão e decisão intersubjetivas"73.

Sua visão é denominada de construtivismo epistemológico e funda-se em conferir legitimidade e validade à decisão da maioria74. Não busca o consenso, entendendo que a democracia deliberativa atua na transformação dos interesses dos indivíduos, ou seja, trata-se de um mecanismo para auxiliar na busca do resultado mais correto.

69 GODOY, Miguel Gualano de. Constitucionalismo e democracia: uma leitura a partir de Carlos Santiago Nino e Roberto Gargarella. p. 90-94.

70 GODOY, Miguel Gualano de. Constitucionalismo e democracia: uma leitura a partir de Carlos Santiago Nino e Roberto Gargarella. p. 95.

71 GODOY, Miguel Gualano de. Constitucionalismo e democracia: uma leitura a partir de Carlos Santiago Nino e Roberto Gargarella. p. 96.

72 GODOY, Miguel Gualano de. Constitucionalismo e democracia: uma leitura a partir de Carlos Santiago Nino e Roberto Gargarella. p. 96

73 GODOY, Miguel Gualano de. Constitucionalismo e democracia: uma leitura a partir de Carlos Santiago Nino e Roberto Gargarella. São Paulo: Saraiva, 2012. p. 101.

74 GODOY, Miguel Gualano de. Constitucionalismo e democracia: uma leitura a partir de Carlos Santiago Nino e Roberto Gargarella. p. 101-102. 
Já Gargarella ensina que democracia deliberativa requer que as decisões públicas sejam pautadas em uma base consensual ampla, formada pelos mais variados setores da sociedade, acreditando que enquanto menor for a intensidade da participação cívica, mais fracas serão as razões para considerar a imparcialidade do resultado final do processo deliberativo 75. Nesse contexto, é ampliada a intervenção coletiva como mecanismo de imparcialidade do procedimento

Porém, pode surgir o questionamento acerca da possibilidade de impor a vontade desejada pela maioria a uma parcela da sociedade que não comunga desse posicionamento. Consequentemente, haveria uma contradição no próprio conceito democrático. Godoy explica que não, sendo imprescindível a distinção entre moral pública e privada. A pública "consiste nos estandartes que permitem ou proíbem e avaliam as condutas exercidas pelos sujeitos e que repercutem sobre uma sociedade", já a privada "é autorreferente, diz respeito às permissões e proibições e avaliações de um sujeito sobre suas próprias condutas" 76.

Como exemplo de moral privada está a opção sexual do indivíduo, não cabendo ao Estado intervir nessa opção, pois ninguém melhor de que o próprio cidadão avalie e escolha suas preferências. Já a distribuição de riquezas seria uma questão que transcende a esfera individual e poderia ser objeto de deliberação pública.

O problema, contudo, é distinguir essas esferas, pois inexiste uma linha que as separa, sendo o exame realizado em cada caso concreto e nos efeitos de determinada conduta a terceiros, se causam danos nas vidas dos demais 77.

De qualquer forma, para que seja eficaz, a democracia deliberativa necessita estar assentada no princípio da igualdade, o qual implica não só conferir tratamento isonômico a todas as pessoas, mas também em assumir que todos têm o mesmo valor moral78. Somente assim, indivíduos poderão participar dos

75 GARGARELLA, Roberto. ¿Democracia deliberativa y judicialización de los derechos sociales?. Perfiles latinoamericanos, julio-diciembre, número 028. Facultad Latinoamericana de ciências sociales. Distrito Federal, México. p. 9-32. p. 19.

76 GODOY, Miguel Gualano de. Constitucionalismo e democracia: uma leitura a partir de Carlos Santiago Nino e Roberto Gargarella. p. 142-143.

77 GODOY, Miguel Gualano de. Constitucionalismo e democracia: uma leitura a partir de Carlos Santiago Nino e Roberto Gargarella. p. 143-144.

78 GODOY, Miguel Gualano de. Constitucionalismo e democracia: uma leitura a partir de Carlos Santiago Nino e Roberto Gargarella. p. 28. 
processos deliberativos em condição de igualdade e auxiliar na transformação da realidade 79 .

Há que se diferenciar, contudo, as concepções liberal e coletivista desse princípio. Sob a ótica do laissez-faire, a sociedade é formada por um conjunto de indivíduos, não pode ser identificada coletivamente e deve separar-se do Estado 80.

A preocupação está em assegurar liberdade para o indivíduo agir conforme suas vontades, sem qualquer poder norteador. Para tanto, devem ser assegurados direitos individuais e a sua grande influência foi o êxito dessa ideologia nos Estados Unidos 81. Agindo assim, questões coletivas poderiam ser dirimidas pelos próprios indivíduos, de forma isolada e não por meio de discussões coletivas. Kozicki denomina essa concepção de liberdade como negativa, pois consiste na ausência de interferência, seja ela política, religiosa, estendendo-se, também, para a liberdade de consciência, expressão, de propriedade 82.

Ocorre que nos países latino-americanos, em especial no Brasil, a aplicação de tal ideologia revelou-se incompatível com a realidade. Buarque de Holanda foi um crítico do positivismo brasileiro e entendia que o legislador brasileiro se valeu de uma concepção destoante do mundo fático, influenciada por conceitos de outros países, sem saber até que ponto isso iria se ajustar às nossas condições de vida 83.

E nesse contexto, aduz que os ideais liberais jamais foram plenamente compreendidos por nós, exceto aquilo atinente à negação de uma autoridade incômoda 84. Como consequência, afirmava que a nossa democracia ocorreu às avessas, tratando-se de um movimento de cima para baixo, de minorias exaltadas, com baixa aderência do povo85. A ideia é compartilhada por Lênio Streck 86

79 GODOY, Miguel Gualano de. Constitucionalismo e democracia: uma leitura a partir de Carlos Santiago Nino e Roberto Gargarella. p. 59-61.

80 GABARDO, Emerson. Interesse público e subsidiariedade: o Estado e a sociedade civil para além do bem e do mal. p. 21-22.

81 GODOY, Miguel Gualano de. Constitucionalismo e democracia: uma leitura a partir de Carlos Santiago Nino e Roberto Gargarella. p. 60.

82 KOZICKI, Katya. Democracia deliberativa: a recuperação do componente moral na esfera pública. p. 44.

83 HOLANDA, Sérgio Buarque de. Raízes do Brasil. 24. ed. Rio de Janeiro: José Olympio, 1992. p. 118-119.

84 HOLANDA, Sérgio Buarque de. Raízes do Brasil. p. 119.

85 HOLANDA, Sérgio Buarque de. Raízes do Brasil. p. 120.

86 STRECK, Lenio Luiz. Jurisdição constitucional e hermenêutica: uma nova crítica do direito. Porto Alegre: Livraria do Advogado, 2002. p. 144. 
quando aborda o paradigma do Estado Social-Intervencionista, aduzindo que as escolhas estatais, em nosso caso, são permeadas por um "querer genético da sociedade", refletindo interesses de grupos no poder. Ato contínuo, o deficit democrático presente nas sociedades em que impera a desigualdade seria um óbice à democracia deliberativa.

Contudo, há o segundo viés da igualdade. Para a postura coletivista, tem-se imprescindível a interferência estatal para equalizar as desigualdades que afetam a sociedade.Trata-sedeum procedimento robusto, confrontadordofigurinoliberal87. Para atingir sua finalidade, esse igualitarismo "se opõe a todas as desigualdades que impliquem prejuízos às pessoas e sejam alheios a sua responsabilidade"88, proporcionando o desenvolvimento da autonomia pública e privada:

Aqui reside a importância da deliberação coletiva como elemento essencial para a tomada de decisões de índole coletivas, já que se parte do pressuposto de igualdade e de que todos merecem igual respeito e consideração. Daí a defesa intransigente de Nino por uma democracia deliberativa que inclua os cidadãos no processo de tomada de decisões. Vale dizer, a democracia deliberativa rearticula soberania e poder constituinte, constitucionalismo e democracia e acentua o caráter produtivo das tensões experimentadas por aqueles, na medida inexorável, porém produtiva, relação que estabelecem entre si ${ }^{89}$.

É a liberdade dos antigos, positiva, "fundada nos ideais de participação política e gerenciamento da coisa pública, implicando liberdades políticas, exercidas no âmbito público"90.

Essa última concepção de liberdade que está ligada à democracia coletiva, conceito que tem raízes ligadas à Grécia Antiga, em que os cidadãos participavam ativamente da política. Ademais, não se tratava de um direito, mas um dever e o ambiente político girava em torno das reuniões nas assembleias.

87 GODOY, Miguel Gualano de. Constitucionalismo e democracia: uma leitura a partir de Carlos Santiago Nino e Roberto Gargarella. p. 65.

88 GODOY, Miguel Gualano de. Constitucionalismo e democracia: uma leitura a partir de Carlos Santiago Nino e Roberto Gargarella. p. 65

89 GODOY, Miguel Gualano de. Constitucionalismo e democracia: uma leitura a partir de Carlos Santiago Nino e Roberto Gargarella. p. 68.

90 KOZICKI, Katya. Democracia deliberativa: a recuperação do componente moral na esfera pública. p. 44. 
Tal postura ativa é o que difere cidadãos atuantes na esfera política daqueles meramente nominais, como bem delineado por Heller e Fehér 91. Os autores explicam que em um estado democrático de direito, todo adulto é um cidadão, porém há aqueles que participam efetivamente da esfera pública, ou seja, que possuem uma "relação prática individual com as normas e regras da esfera política"92. E essa possibilidade independe de vocação política.

Por conta disso, pode-se afirmar que a sociedade é política e, assim sendo, "[...] precisa ser republicana, sob pena de um retrocesso em face dos avanços civilizacionais promovidos pela modernidade" ${ }^{\prime 93}$.

Sabe-se que, em uma sociedade plural, o dissenso é inevitável, pois raramente as pessoas irão convergir sobre as suas concepções de bem comum. Contudo, a ideia é buscar neutralizar o dissenso pela ética do discurso, pela aceitação racional, mediante o acordo mútuo. Nesse contexto, ganha espaço a ideia de democracia deliberativa, a qual preconiza a ideia de que somente se pode atingir um consenso sobre tolerância mútua sobre formas de vida quando se tem uma base constituída em convicções em comum, nem que isso seja a favor do "agree to disagree".

Kozicki define bem esse raciocínio, explicando que "a ideia é a de uma racionalidade articulada intersubjetivamente na comunicação e que se orienta para a compreensão mútua"94.

Pessoas vão divergir acerca de concepções religiosas, políticas, culturais, econômicas. Conforme exposto anteriormente, o figurino liberal determinava neutralidade quanto ao tema. Já com a formulação de princípios de justiça, acredita-se que pode ser atingido um consenso racional ${ }^{95}$.

Nesse contexto, advém a importância do pensamento de Nino, que entende ser necessária a defesa de direitos das minorias e de certos valores morais, os quais não podem ser objetos de questionamento.

91 HELLER, Agnes, FEHÉR, Ferenc. A condição política pós-moderna. Tradução de Marcos Santarrita. 2. ed. Rio de Janeiro: Civilização Brasileira, 2002. p. 115.

92 HELLER, Agnes, FEHÉR, Ferenc. A condição política pós-moderna. p. 115.

93 GABARDO, Emerson. Interesse público e subsidiariedade: o Estado e a sociedade civil para além do bem e do mal. p. 369.

94 KOZICKI, Katya. Democracia deliberativa: a recuperação do componente moral na esfera pública. p. 46.

95 KOZICKI, Katya. Democracia deliberativa: a recuperação do componente moral na esfera pública. p. 47. 
Em outros termos, a "democracia deve ser adotada como procedimento e experimentação numa ação comunicativa e argumentativa, a fim de serem tomadas as decisões moralmente mais corretas" $" 96$

Aqui está o ponto central do trabalho, atinente às reformas previdenciárias e, em especial, à DRU. O dissenso é inevitável, assim como as mudanças. Contudo, não se observa, na experiência brasileira, a ação comunicativa, dialógica, o que poderia ocorrer por meio de audiências públicas e debates entre as mais variadas classes da sociedade.

Em âmbito previdenciário, as mais recentes alterações ocorreram por meio de medidas provisórias e, no caso da última deliberação da DRU, sequer o regimento interno da câmara foi respeitado. Em ambos os casos, a vontade popular foi relegada para atingir maior celeridade.

Não é o procedimento que parece ser o mais indicado, mormente quando se trata de um direito social fundamental, cujas prestações apresentam caráter alimentar. Assim, para que sejam tomadas decisões moralmente mais corretas, indispensáveis o resgate da esfera pública e a democracia deliberativa.

Diz-se isso porque somente a democracia, por meio da exposição, da deliberação pública, proporcionará a integração social e, assim, o reconhecimento da pluralidade de interesses, sendo indispensável a preparação dos indivíduos para a participação na vida pública ${ }^{97}$.

\section{CONSIDERAÇÕES FINAIS}

O presente trabalho teve como objetivo apresentar considerações a respeito do financiamento da Seguridade Social e o impacto ocasionado pela DRU, a qual compromete o equilíbrio financeiro-atuarial do sistema assecuratório.

Ao mesmo tempo em que se ouve a respeito do deficit previdenciário, a DRU permanece sendo renovada e a última alteração majorou para 30\% o total a ser

96 GODOY, Miguel Gualano de. Justiça. Democracia e Direitos Fundamentais: o liberalismo igualitário de John Rawls, o procedimentalismo e Jürgen Habermas e a proposta de Carlos Santiago Nino. In: XIX Encontro Nacional do Conselho Nacional de Pesquisa e Pós-graduação em Direito (CONPEDI), 2010, Fortaleza. Anais do XIX Encontro Nacional do Conselho Nacional de Pesquisa e Pós-graduação em Direito, 2010. p. 4548.

97 GABARDO, Emerson. Interesse público e subsidiariedade: o Estado e a sociedade civil para além do bem e do mal. p. 378-379. 
desvinculado daquilo arrecadado pela União a título de contribuições sociais, de intervenção no domínio econômico e taxas. Ademais, vale ressaltar que sequer o regimento interno da Câmara dos Deputados foi respeitado, sob o argumento da necessidade de urgência no trâmite.

Em contrapartida, observam-se reformas no sistema previdenciário fundadas na necessidade de equalização das contas, bem como medidas mais restritivas de direitos em relação aos segurados, como foi a instituição da contribuição previdenciária sobre os inativos.

Consequentemente, o argumento revela-se contraditório. Ao mesmo tempo, não são observadas iniciativas populares questionando esse tipo de procedimento, responsável por afetar diretamente a população. Nesse contexto, a fim de buscar apresentar uma solução para o problema desenhado, apresentaram-se a necessidade de resgate da esfera pública e a importância da democracia, por meio da deliberação pública para atingir os objetivos republicanos.

Emquepeseexistirtensãoentreosideais democráticosedo constitucionalismo, a deliberação pública apresenta-se como um mecanismo de atenuar essa relação e somente será concretizada com a construção de um espaço público.

Apresentou-se o pensamento de Rawls, Habermas, Godoy, Gargarella e Nino. Os dois últimos vão além do modelo substancial de Rawls e procedimental de Habermas, propondo a importância de um procedimento legítimo e justificador, que ocorre por meio de procedimentos de discussão entre os indivíduos.

Assim, a democracia deliberativa releva-se como um mecanismo importante para troca de informações, bem como para estabelecer as bases para decisões moralmente mais corretas na matéria previdenciária, sendo indispensável, para tanto, o resgate da esfera pública e uma maior participação dos cidadãos na política, promovendo debates, expondo pontos de vista e discutindo sobre assuntos que estão sendo deixados de lado. Assim, restará afetado não só o exercício da cidadania, mas também o sistema brasileiro de Seguridade Social. 


\section{REFERÊNCIAS DAS FONTES CITADAS}

ANÁLISE DA SEGURIDADE SOCIAL 2014/Associação Nacional dos Auditores-Fiscais da Receita Federal do Brasil e Fundação ANFIP de Estudos da Seguridade Social - Brasília: ANFIP, 2015, p. 135. Disponível em: <http://www.anfip.org.br/publicacoes/20150713162859_Analise-daSeguridade-Social-2014_13-07-2015_20150710-Anlise-Seguridade-2014-Verso-Final.pdf > . Acesso em 20 jul. 2016.

BARROSO, Luís Roberto. Constituição, democracia e supremacia judicial: direito e política no Brasil contemporâneo. Revista eletrônica sobre a reforma do estado (RERE). Salvador, Instituto brasileiro de direito público, n 23, setembro, outubro, novembro, 2010. Disponível em: <http://www.direitodoestado.com/ revista/rere-23-setembro-2010-luis-roberto-barroso. pdf>. Acesso em 01.jul. 2016. p. 16.

BERCOVICI, Gilberto. Constituição e política: uma relação difícil. Lua Nova. São Paulo, n. 61, p. 5-24. 2004.

BRASIL, Supremo Tribunal Federal, Recurso Extraordinário no 566007 RG, Relator(a): Min. CÁRMEN LÚCIA, julgado em 13/05/2010, DJe-116 DIVULG 24-06-2010 PUBLIC 25-06-2010 EMENT VOL-02407-05 PP-01043 LEXSTF v. 32, n. 379, 2010, p. 219-225 RET v. 13, n. 75, 2010, p. $123-127$

BRASIL. Câmara doa Deputados. Discursos e Notas Taquigráficas - Sessão: 140.2.55.0. Disponível em: <http://www.camara.leg.br/internet/sitaqweb/Texto HTML.asp?etapa=3\&nu Sessao $=140.2 .55 .0 \&$ nuQuarto $=7 \&$ nuOrador $=1 \&$ nuInsercao $=0 \& d$ thorarioQuarto $=20: 20 \&$ sgFaseSessao=BC\%20\%20\%20\%20\%20\%20\%20\%20\&Data=07/06/2016\&txApelido=PRESI DENTE\&txFaseSessao=Breves\%20Comunica\%C3\%A7\%C3\%B5es\%20\%20\%20\%20\%20\%20 \%20\%20\%20\%20\%20\&dtHoraQuarto=20:20\&txEtapa=Com\%20reda\%C3\%A7\%C3\%A3o\%20 final> Acesso em: 20 jul. 2016.

BRASIL. Câmara dos Deputados. Projetos de Lei e outras proposições. PEC 87/2015. Disponível em: <http://www.camara.gov.br/proposicoesWeb/ fichadetramitacao?idProposic ao $=1567815>$ Acesso em: 20 jul. 2016.

BRASIL. Câmara dos Deputados. Projetos de Lei e outras proposições. PEC 4/2015. Disponível em: <http://www.camara.gov.br/proposicoesWeb/prop_mostrarintegra?codteor $=1465821 \&$ filename=Tramitacao-PEC+4/2015> Acesso em: 20 jul. 2016.

BRASIL. Previdência Social. RGPS: Regime Geral de Previdência Social tem déficit de 51,3 bilhões em 2013. Disponível em: < http://www.previdencia.gov.br/ noticias/regime-geral-deprevidencia-social-tem-deficit-de-513-bilhoes-em-2013/>. Acesso em: 20 jul. 2016.

BRASIL. Secretaria do Tesouro Nacional. Receitas Primárias do Governo Central. Disponível em: <http://www3.tesouro.fazenda.gov.br/series_temporais/ Visualizacao.asp $\mathrm{x}$ ? mudarperiodicidade $=\mathrm{N} \&$ variacaoabsoluta $=\mathrm{N} \&$ nabsoluta $=$ \&variacaopercentual $=\mathrm{N} \& \mathrm{n}$ percentual = \&mediamovel = N\&nmedia = \&metodomedia =Selecione\%200\%20M\%C3\%A9todo\&periodicidade=Selecione\%20a\%20Mudan\%C3\%A7a\&metodo=Selecione\%20o\%20 
Crit\%C3\%A9rio\&novabase = \&indice=N\&deflacionar=N\&strdeflator $=$ Selecione\%200\%20Deflator\&deflator=\&basedeflator=\&inicio=\&fim=> Acesso em: 20 jul. 2016.

BRASIL. Senado Federal. Agência Senado. DRU. Disponível em: <http://www12.senado.leg. br/noticias/entenda-o-assunto/dru> Acesso em: 20 jul. 2016.

CANOTILHO, José Joaquim Gomes. Direito constitucional e teoria constitucional. 2. ed. Coimbra, Almedina, 1988.

DE SANTI, Eurico Marcos Diniz; CANADO, Vanessa Rahal. Direito Tributário e direito financeiro? Reconstruindo o conceito de tributo e resgatando o controle da destinação. In: Curso de direito tributário e finanças públicas: do fato à norma, da realidade ao conceito jurídico. $1^{a}$ edição, $2^{a}$ tiragem, 2009.

ESTADÃO. Previdência fecha 2013 com deficit de $\mathbf{R} \mathbf{\$ 5 1 , 2}$ bilhões. Disponível em: <http://economia. estadao.com.br/noticias/geral,previdencia-fecha-2013-com-deficit-de-r-51-2-bilhoes,176679e> Acesso em: 20 jul. 2016.

GABARDO, Emerson. Interesse público e subsidiariedade: o Estado e a sociedade civil para além do bem e do mal. Belo Horizonte: Fórum, 2009.

GABARDO, Emerson; VALIATI, Thiago. A inconstitucionalidade da instituição de contribuição previdenciária para servidores inativos. Revista de Direito Administrativo, v. 270, p. 243-282, 2015.

GARGARELLA, Roberto. ¿Democracia deliberativa y judicialización de los derechos sociales?. Perfiles latino-americanos, julio-diciembre, número 028. Facultad Latinoamericana de ciências sociales. Distrito Federal, México. p. 9-32.

GARGARELLA, Roberto. Constitucionalismo vs. Democracia. In: ZAMORA, Jorge Luis Fabra; SPECTOR, Ezequiel. Enciclopedia de filosofia y teoria del derecho. Volumen três. México: Universidad Nacional Autónoma de México, 2015. p. 1991-2010.

GODOY, Miguel Gualano de Godoy. Constitucionalismo e democracia: uma leitura a partir de Carlos Santiago Nino e Roberto Gargarella. São Paulo: Saraiva, 2012.

GODOY, Miguel Gualano de. Justiça. Democracia e Direitos Fundamentais: o liberalismo igualitário de John Rawls, o procedimentalismo e Jürgen Habermas e a proposta de Carlos Santiago Nino. In: XIX Encontro Nacional do Conselho Nacional de Pesquisa e Pós-graduação em Direito (CONPEDI), 2010, Fortaleza. Anais do XIX Encontro Nacional do Conselho Nacional de Pesquisa e Pós-graduação em Direito, 2010.

GRECO, Marco Aurélio. Contribuições: uma figura sui generis. São Paulo: Dialética, 2000.

HABERMAS, Jürgen. A inclusão do outro: estudos de teoria política. Tradução de George Sperber, Paulo Soethe e Miltin C. Mota. 2. ed. São Paulo: Loyola, 2004.

HABERMAS, Jürgen. Direito e democracia: entre facticidade e validade, volume I. Tradução: Flávio Beno Siebeneichler. Rio de Janeiro: Tempo Brasileiro, 1997. 
HELLER, Agnes, FEHÉR, Ferenc. A condição política pós-moderna. Tradução de Marcos Santarrita. $2^{a}$ ed., Rio de Janeiro: Civilização Brasileira, 2002.

HOLANDA, Sérgio Buarque de. Raízes do Brasil. 24. ed. Rio de Janeiro: José Olympio, 1992.

KOZICKI, Katya. Democracia deliberativa: a recuperação do componente moral na esfera pública.

Revista da Faculdade de Direito da UFPR. Curitiba. v. 41. 2004.

NINO, Carlos Santiago. La constitución de la democracia deliberativa. Buenos Aires: Gedisa, 1997.

PAULSEN, Leandro; VELLOSO, Andrei Pitten. Contribuições: teoria geral, contribuições em espécie. Porto Alegre: Livraria do Advogado Editora, 2013.

RAWLS, John. Uma teoria da justiça. Tradução: Almiro Pisetta e Lenita M. R. Esteves. São Paulo: Martins Fontes, 1997.

REVISTA EXAME. Déficit da Previdência no $\mathbf{1}^{\mathbf{0}}$ semestre foi de $\mathbf{R} \mathbf{2 3}$ bi. Disponível em: <http://exame.abril.com.br/economia/noticias/deficit-da-previdencia-no-1o-semestre-foide-r-23-bi>. Acesso em: 20 jul. 2016.

SCHOUERI,Luís Eduarda. Normas tributár $\Delta / \Delta$ lutoras e intervenção econômica. Rio de Janeiro: Forense, 2005.

STRECK, Lenio Luiz. Jurisdição constitucional e hermenêutica: uma nova crítica do direito. Porto Alegre: Livraria do Advogado, 2002. 